\title{
A Review of the School Science Curricula in Eleven High Achieving Jurisdictions
}

\section{Martin Hollins and Michael J Reiss}

The last two decades have seen unprecedented interest in science curricula, with many governments seeing improvements in the performance of their school students in science as key to future economic prosperity. We present the results of an analysis of the curriculum documents for primary and secondary science in Australia (New South Wales and Queensland), Canada (Alberta and Ontario), Finland, Japan, Singapore, Hong Kong, Shanghai and The United States (Florida and Massachusetts). Beyond our specific findings, we note a degree of convergence across these eleven very different jurisdictions. The Asian ones have made and are making changes to encourage students to be more creative and better able to apply their science knowledge and develop their scientific literacy; the 'Western' ones are becoming more knowledge-focused.

Keywords: school science, curricula, assessment, International Instructional Systems Study

\section{Context}

Worldwide, the last two decades have seen unprecedented interest in science curricula (e.g. Freeman et al., 2015). In part this interest has resulted from both the three-yearly OECD Programme for International Student Assessment (PISA) reports which, since the year 2000, have provided an international league table of country performance in reading, mathematical literacy and scientific literacy and the four-yearly Trends in International Mathematics and Science Study (TIMSS) reports, since 1995, of country performance in mathematics and science. Alongside this, the forces of globalisation have meant that more and more governments see improvements in the performance of their school students in STEM (Science, Technology, Engineering and Mathematics) subjects as vital 
if their country is to improve its position in a global race towards economic prosperity driven by STEM professionals.

This belief can be criticised on a number of grounds. How valid are such neoliberal arguments? Do we not want school STEM curricula to be about more than producing the next generation of STEM professionals (Ryder \& Banner, 2011)? Aren't pedagogies more important than curricula (Hattie, 2009)? Nevertheless, interest in school science curricula and their accompanying assessment arrangements continues apace. It is therefore timely to examine the science curricula of high achieving jurisdictions not with a view to naïve policy borrowing but to see what can be learnt from such jurisdictions. Specifically, this article is based on detailed reviews of the curriculum documents for primary science, secondary biology, secondary chemistry, secondary physics and secondary Earth science that we undertook in the following eleven jurisdictions: Australia (New South Wales and Queensland), Canada (Alberta and Ontario), Finland, Japan, Singapore, Hong Kong, Shanghai and The United States (Florida and Massachusetts) for the International Instructional Systems Study (hereafter the Study) (CIEB, 2015) (see Creese, Gonzalez \& Isaacs, this issue). While Florida cannot really be described as a high achieving jurisdiction the Study's funder was keen to include a US state that contrasted with Massachusetts.

The reviews focussed on the following aspects of the curriculum documents:

- the context of the curriculum in each jurisdiction

- the coherence and clarity of its presentation

- the scope, progression, levels of demand and key competences of the content presented

- assessment arrangements.

This paper therefore explores the similarities and differences between the science curricula in these jurisdictions and discusses current issues and potential developments in the curricula, raised through these reviews. We see our work as building on that of a recent report for the UK government (DfE, 2012), which made comparisons between the 
English, mathematics and science curricula of a number of jurisdictions (five for science: Victoria, Australia; Alberta, Canada; Hong Kong; Singapore; Massachusetts, USA) and those of England. Understandably, the focus of the DfE report was on lessons that could be learnt from other jurisdictions that would be of benefit to England. In science a key finding was that the National Curriculum for science that was current at the time in England (the 2007 version) was "not specific enough to assess the level of challenge" (DfE, 2012, p3). Our work also relates to that of Freeman et al. (2015), who look at educational policy and practice across the world in STEM subjects (science, technology, engineering and mathematics), whereas we concentrate on aspects of the science curricula of high-performing jurisdictions. Throughout, we raise questions that arise from our review that we believe are relevant to science educators and those involved in curriculum development.

\section{Goals for science education}

Goals for science education are set out in the introduction to the curriculum documents provided for each jurisdiction and usually relate to the context of schooling in each jurisdiction (Isaacs, Creese \& Gonzales, 2015a). A notable aspect of the curricula of these jurisdictions is that most are involved in change of some kind. In Australia and Canada, the curriculum is developed in collaboration between the Federal and State or Province governments. In New South Wales and Queensland there are new curricula; in Ontario one was introduced in 2013 and Alberta there is a currently a review. In Singapore a new curriculum was introduced in 2014. There are also reviews in progress in Japan, Hong Kong and Shanghai and in Finland there is to be a review in 2016. Florida in the USA began in 2012 a five-year strategic plan for its education system. The last major change to the Massachusetts curriculum, by contrast, was undertaken in 1993.

The features of the current and prospective changes have much in common. There are intentions to emphasise: scientific literacy; enquiry and the nature of science; science and technology in the modern world. There are also personal and social goals to be 
strengthened, including learning how to learn, critical thinking skills and social attitudes and values. The differences in the ways these are expressed reflect to some extent the developmental backgrounds of the curricula in the various jurisdictions.

The goals are driven by local and national needs, but there is increasing awareness of international comparisons. For example, the Florida curriculum has an explicit goal of having a world-class education system that engages and prepares all students to be globally competitive for college and careers. Science is seen as an important part of the school curriculum, from the earliest years, providing a broad coverage of the subject, developing from integration across the sciences, including a core of biology, chemistry and physics to options later, with more academic or vocational or technical orientations.

Most curricula recognise the importance of links to mathematics, literacy, technology and health. The more personal skills of team working, problem solving and creativity are less commonly recognised, and the relationship of school science to science in the world at large is neglected in some specifications. Massachusetts has a strong emphasis on handson laboratory and field experiences.

The differences between the jurisdictions in their goals for science education seem greater than the differences between them, as discussed below, in their content. Those involved in future curriculum development might profitably ask themselves whether such differences are warranted. Given international moves towards greater coherence in science curricula (e.g. Harlen et al., 2010), might we expect greater coherence in the goals of science education, or is it the case that local differences warrant considerable divergence in these goals?

\section{Overview of science content}

All of the jurisdictions have extensive documentation on the curriculum; the nature of its science content can support coherence and its organisation can aid its clarity. Most of the 
jurisdictions have documents for a series of grades. For example, Australia has a document for each year; Shanghai for each two-year period. Within a jurisdiction, these are identical in format to aid coherence, where appropriate, allowing for different course options at the later stages. The level of detail varies significantly between jurisdictions and there are differences of documentary complexity, particularly in the post-compulsory stage. Singapore is probably the most complex with several partially overlapping routes.

Documentation is typically full of generic advice and instruction, which can obscure the distinctiveness of the stage or course. For example, the Queensland physics documents for years 8, 9 and 10 each contain only one page of physics content in a 50-page document; the upper secondary document of Finland is 250 pages with 30 pages for science content specification. Whilst the Queensland approach may serve to provide a good overview of purpose across the curriculum, it does not offer clarity on what the expectations are about the learning of specific elements of science. One might conclude that the generic is easier to describe, or that the authors of the advice do not wish to be too prescriptive about classroom practice.

For each jurisdiction, the content relates the overarching aims and purposes of the curriculum to specific content requirements. In science the aims are typically grouped into three aspects: knowledge and understanding; skills and application; values and attitudes. From these generic aspects the documents may identify themes, or 'big ideas' (cf. Harlen et al., 2010) as mid-level organisers, before presenting detailed learning objectives. These learning objectives may then be exemplified by possible classroom activities, though this is rare. Shanghai, for example, has three levels of detailed description, suggested outcomes and extension material. Hong Kong provides a good example of how the different aspects and levels of description can be presented - notably by the use of a 3D-diagram displaying the interrelated dimensions of the nature of science, key ideas and unifying concepts. 
The interconnection of the generic aspects of the curriculum to the details of specifics is useful as it is possible that specialist science teachers will not pay attention to purely generic aims and goals but only to those which explicitly fall under science headings.

\section{Specification of science content}

Comparisons of the scope, progression, levels of demand and key competences are often difficult to make due to the different ways that these are presented. For example, in the specification of the primary stage (typically ages 6-12; see Table 1) the number of objectives listed range from 24 for Finland to 350 for Ontario! This does not relate to the extent of the science curriculum, rather to the specificity of the statements.

Ontario presents the curriculum content at three levels of detail; for example, within Grade 9 Biology:

- Big ideas: People have the responsibility to regulate their impact on the sustainability of ecosystems in order to preserve them for future generations

- Overall expectations: Investigate the factors related to human activity that affect terrestrial and aquatic ecosystems, and explain how they affect the sustainability of these ecosystems

- Specific expectations: Students will assess, on the basis of research, the impact of a factor related to human activity (e.g. urban sprawl, overhunting/fishing) that threatens sustainability of a terrestrial or aquatic ecosystem.

Finland presents the content in a small number of general statements, e.g. Learn to discern the structure and operation of ecosystems, but these are accompanied by performance descriptors and assessment criteria, e.g. Analyse a population in terms of its main groups and justify the grouping, which provide a clearer picture of the scope of the content statements. Finland also has a very substantial generic description of the curriculum so that it is clear that Finnish teachers have more scope for local adaptation of the national curriculum within these broader guidelines. 
In Florida and Massachusetts, the statements are 'standards' and are prefaced with a command word drawn from Bloom's taxonomy, which provides a concise indication of the demand. Most others are more descriptive of content.

The primary phase is arranged in two distinct stages in several of the jurisdictions, with the first stage, usually to the age of seven, focussing on engagement, observation and description of the natural world. This is particularly evident in Japan, Hong Kong and Shanghai. The integration of science with other subject areas is common; for example, in Hong Kong throughout years 1-6, science is part of general studies which includes personal, social, humanities and technology education. In several cases the science emerges throughout the primary phase and usually consists of strands covering living things, matter and energy. About half of the jurisdictions include Earth science and Earth in space, and some have substantial technology content. All jurisdictions have knowledge and understanding objectives and most list the skills of scientific working. There are notable differences of emphasis with Finland providing the greatest degree of integration of subjects with the minimum of detail, whilst Japan's specification is full of content, but neglects to stress science skills, both practical and intellectual, and Singapore provides a strong emphasis on values and attitudes.

Both Hong Kong and Shanghai have distinctive general objectives around the impact of science and technology on society, perhaps reflecting the urban societies which the curricula in these two jurisdictions serve. Hong Kong has Science Technology and Society as one of four themes throughout the curriculum and Shanghai has within the domain of knowledge, that related to the application of science to solve problems and the work of scientists and their impact on human activity.

For the secondary phase, the curriculum is organised into two blocks for all the jurisdictions, a compulsory junior phase, usually of three years, and electives within a senior phase also usually of three years. Variants are in Australia, Canada and Shanghai where the junior phase is usually four years and the senior two years. The end of the first 
phase coincides with the end of compulsory schooling in all jurisdictions, except for Ontario where it is later and Singapore where it is earlier. Typically, the full range of sciences is studied by all in the first phase, though Earth science may be located in geography rather than science. Separation into biology, chemistry and physics occurs in most at the start of the second phase with a range of electives, so that (with the exception of Shanghai), learners need not study science at this stage. The range of electives always includes biology, chemistry and physics, sometimes in pairs or integrated across all three. There are several ways in which the approaches are differentiated, usually as academic (or general) and technical/vocational. This differentiation is also intended to present different levels of demand, though this is generally not stated, and in several jurisdictions there are parallel courses with greater and lesser demands. Singapore has the most differentiation in this way, starting in the primary stage and continuing to diversify until school leaving age. Many jurisdictions provide extension material to increase the demand for the more able, and such material is assessed; only New South Wales appears to have a curriculum called 'Life Skills', designed specifically for the less able. Indications of demand levels may be provided through performance descriptors and assessment criteria, which may be for a stage of two to four years, rather than a single year.

The Hong Kong presentation clearly provides the demands of the curriculum at each level, from the detailed specification of the Learning Objectives (LOs), amplified by the matched Suggested Teaching and Learning Activities. There is consistent attention to the range of abilities at each stage, with core and extension suggestions. Teachers are encouraged and supported in their own course construction, to match demand to the range of abilities in a class. Progression is apparent in the detail of the LOs for the different stages, and also in the general curriculum guide. Similar clarity of demand is apparent in the Shanghai curriculum; extension material is provided and the use of research projects is also an aid to differentiation. The inclusion of modern science can also extend the demand. For example, in physics Grade 6-7, Electricity and telecommunications includes a section on telecommunications, which includes modern equipment, future developments and, as an extension, the semiconductor chip. Singapore has a highly differentiated approach throughout secondary, which indicates that demand is a 
significant consideration in the curriculum requirements. In general, the demand in the Singapore curriculum is high, through breadth of coverage, rather than depth of treatment - there is an apparent lack of explanation or higher order thinking in the specified outcomes. Progression is clear in each of the different routes. The most recent revisions to the curriculum framework of Massachusetts gave additional attention to progression, and are particularly useful in relation to scientific inquiry.

The jurisdictions vary in their presentations of Key competencies. Most have aims expressed in generic terms, about the science curriculum developing enquiry skills, scientific or critical thinking, communication skills and personal skills. The differences are in whether these are specifically included as learning objectives, separately or integrated with science content. Many of the jurisdictions do not appear to address these in the assessment methods, which would tend to lead to their neglect. Florida intends that forthcoming assessments will include students' higher-order thinking skills. Ontario spells out in most detail what it considers scientific thinking to consist of:

Critical thinking is the process of thinking about ideas or situations in order to understand them fully, identify their implications, and/or make a judgement about what is sensible or reasonable to believe or do. Critical thinking includes skills such as questioning, predicting, hypothesizing, analysing, synthesizing, examining opinions, identifying values and issues, detecting bias, and distinguishing between alternatives. Critical literacy is the capacity for a particular type of critical thinking that involves looking beyond the literal meaning of a text to determine what is present and what is missing, in order to analyse and evaluate the text's complete meaning and the author's intent. Critical literacy goes beyond conventional critical thinking by focusing on issues related to fairness, equity, and social justice (Ministry of Education, 2007, p38).

The documents make it clear that these two competencies of critical thinking and critical literacy should be developed as learners develop their scientific investigation skills. 
Japan and Singapore are attempting to change the curriculum from one more concerned with science content to one that promotes such competencies. In Japan this is through the introduction of periods of Integrated Study. Commentators on Singapore's attempts consider that the assessment methods militate against this change (Hogan, 2014; Leong et al. 2011). Hong Kong includes in the Diploma of Secondary Education the assessment of creativity, critical thinking skills, communication skills and problem-solving skills in both practical and non-practical related tasks.

What is most apparent in the detailed review of these specifications is that there is no common agreement on the best way to set out the science curriculum, nor on the importance of related issues such as integration of subject content, differentiation of demand and what the key competencies are. Again, the question arises as to whether the science teacher will pay much attention to the generic aspects, such as key competencies, compared to science specifics.

The following sections explore some of these curriculum issues.

\section{Integration and separation of science subjects}

As noted above, all jurisdictions start science in the primary stage by integrating across the core areas of biology, chemistry and physics. Science often includes also earth science and astronomy, and may range across the humanities as well. By the start of the secondary stage all jurisdictions have a curriculum in which all students study the full range of science, though there is some variation in the terms used and in the precise way in which science is divided up; for example, Massachusetts refers to 'physical science' and 'biology'. The end of this stage coincides with the end of compulsory schooling in some jurisdictions, so it is not surprising that choices of differentiated pathways are offered at this stage. These vary greatly between jurisdictions, but one of the drivers is consideration of the next stage for the student, leading to academic/general courses and vocational/technical courses. The latter are more restrictive in their scope and may offer 
choices of modules within a course. The former emphasise the traditional trio of biology, chemistry and physics and may be offered as either separate subjects (more common in the higher demand courses) or integrated (in more general education courses).

Japan has two options for each subject in the elective phase: basic and advanced. The advanced course specifications are designed, in their depth of treatment, to encourage further study. In Singapore the curricula are distinctive in being differentiated into three streams through the compulsory phase as well as beyond. In the elective phase, different courses are provided in different institutions, so the system is complex and diverse. Hong Kong has a wide range of subject combinations within the three sciences: integrating all three (a selection retaining depth but not breadth), taken as a pair, or specialising in biology, in chemistry or in physics. Shanghai is unique in requiring the study of all the sciences throughout the second phase. There is a clear development of the subjects but also opportunity for research by all and suggested extension material for the more able. In the second phase there is a notable coverage of modern science, for example biotechnology and its applications. There is also a clear emphasis on the social impact of science and technology in the research suggestions.

As noted earlier, there are commonly links between science and technology. These are distinctive in Alberta, with the use of Focusing Questions, for example in the Science 10 course in the topic Energy in Global Systems: How can we reduce our impact on the biosphere and on global climate, whilst still meeting human needs? All jurisdictions, apart from Shanghai, have the option of vocational/technical courses in upper secondary (Grades 10/11-12). These have not been reviewed in detail but are intended to lead to alternative progression routes to university or college.

In general, there is an association of increasing separation of science subjects (e.g. biology as opposed to chemistry) with age and with ability. This common practice may be questioned in two ways:

- Would less able students benefit from more focussed and limited breadth of coverage of science, less complicated by integrations? 
- Do those who aspire to pursue science beyond school need more exposure to integration across the sciences as there is more inter-disciplinary work by practising scientists and technicians?

\section{Special education}

There is a surprising omission in most of the documentation on the provision for those learners with sensory impairments or intellectual/learning disabilities. One course that makes explicit reference to such students is in New South Wales for Grades 7-10, 'Life Skills' for a small percentage of students with special education needs, particularly those with an intellectual disability. The overview for Australia states that Types of special provision available can vary widely, both between states and between individual schools. Most school systems do, however, encourage, wherever possible, the mainstream education of students with special educational needs. The fullest account of curriculum provision is given in the Queensland overview Programmes are documented in Individual Education Plans (IEPs) and delivered by special education teachers and support staff, including therapists, nurses and specialist advisory teachers (Isaacs, Creese \& Gonzales, 2015b, p101).

The most inclusive, non-directed approach is found in Finland, where Special Educational provision is part of the core value of inclusiveness, and all students, even those with severe learning difficulties, receive a similar basic education. Every student has the opportunity to progress through to university. Most students with special education needs are mainstreamed within regular classrooms and are provided with part-time special education in small groups, led by specialist teachers. These students generally have an individual learning plan that helps them reach their learning goals. (Isaacs, Creese \& Gonzales, 2015c, p5).

Hong Kong and Singapore have a similar approach, with a combination of provision for learners in mainstream and special schools. Singapore has Special Schools for the 
visually and hearing impaired, and for learning disabilities. Hong Kong states that provision in Special Schools should take a whole school approach.

It is notable, though, that there is nothing in the science documentation that is specific to science education for students with special educational needs. We are somewhat at a loss to account for this. Is it the case that those responsible for curriculum development in science are ignorant of the science-specific literature on special needs education (e.g. Villanueva et al. 2012; Abels, 2014)? Or is it that there is a presumption that students with special educational needs can be ignored in regards to their science education? Hopefully, there is a less worrying reason.

\section{Teaching, schools and other local factors}

It is apparent that the curriculum documents reflect both the expectations of teachers and the nature of schools in each jurisdiction. This is rarely made explicit, though is often implicit in current developments in the light of international comparisons. To make two broad generalisations:

- Asian jurisdictions have had very prescriptive curricula, implying a relatively didactic pedagogy. These are now being opened up to provide more exploratory and student-oriented specifications.

- 'Western' jurisdictions are tending to develop in the opposite direction, with rather tighter specifications both for content and for teaching expectation.

One might conclude that, very broadly, we can see recent developments as a 'regression to the mean'.

The curriculum specifications do not generally contain other than generic pedagogical requirements and advice. For example, the Singapore ' $O$ ' and 'A' level specifications are brief and follow the style of examination syllabuses, which are taught with the support of 
textbooks. In Hong Kong the documentation provides ample specification and exemplification of different content areas and of how knowledge, skills and pedagogy relate. The support and advice for teachers in curriculum documents is strong, and it is notable that much emphasis is placed on the teacher to design the detail of the curriculum for their students' needs, for example in the order in which content is studied, the type of practical work carried out and the nature of school assessed tasks. To support this there is a substantial section of the key curriculum document devoted to 'curriculum planning'. New South Wales provides a range of general advice, such as substantial allocation of time for practical experiences, research projects and relevant contexts for science. In Queensland sources of support for classroom teaching and learning, including websites, are referenced in the documents. Massachusetts provides detailed vignettes of classroom practice to illustrate how to teach a particular standard, which provides the context of the lesson, how the teacher managed it and what the students did and achieved.

There are few indications, other than these exemplars of classroom practice, as to the nature of the schooling in which the science curriculum fits. This therefore raises a number of questions. For example: (1) In the light of science emerging in the primary phase from integration with other subjects - to what extent are the teachers confident in science themselves? (2) The time allocation for science in Finland is greater than other jurisdictions, though they start science later - how does time allocation affect the teaching and learning of science? (3) In Singapore there is differentiation of science courses very early followed by provision in separate institutions, which would appear to introduce pressures within the system - what impact does this have on student achievement?

\section{Assessment and accountability}

The jurisdictions vary considerably in their assessment arrangements, which reflects, to some degree, the nature of accountability in each. Assessment, of course, can be used for several purposes, among them: 
- Monitoring of student progress

- Recognition of student achievement

- Monitoring of school and teacher effectiveness.

These issues are common to all subjects. In science education these issues are supplemented by the question of how, if at all, the practical work that students undertake should be assessed and whether, and again, if so, how, socio-scientific and ethical issues should be assessed.

Jurisdictions vary greatly in the extent of their use of internal, school-based, teacher assessment and external examinations for their assessment of science. In general, the latter predominate at upper secondary, the former during primary. The extreme examples from these jurisdictions are: Ontario, which has no external examinations, and Finland, which has only the matriculation examination at the end of schooling, Grade 12, and, at the other end of the scale, Singapore with the first examination at Primary 4 to determine entry to standard or foundation courses in P5.

The four Asian jurisdictions are in the process of reform to reduce the strong examination culture of assessment, by the provision of extensive guidance on assessment for learning and school-based assessment. Commentators have noted that the reforms are not without resistance, given a prevalence of competition for entry to prestigious schools and $\mathrm{HE}$ institutions (Takayama, 2013; Walker \& Quian, 2012; Curdt-Christiansen \& Silver, 2013; Carless, 2011).

Formative assessments are those used to monitor students' progress. They will usually be school-based (SBA) and may be focussed on progress in student learning, usually called assessment for learning (AfL). In New South Wales years K-10 use SBA with continuing AfL and summative judgements on a 5-point scale twice a year, which provide a report to the learner's parents/carers. The state expands on the national guidance on SBA and encourages self-assessment and peer assessment. Queensland has a similar emphasis on SBA and AfL presented as: Standards-based assessment - teachers are required to report 
performance twice a year against the Australian Curriculum achievement standard drawing on the folio of a child's work - and School-based assessment - teachers and groups of teachers decide the evidence of learning to be collected as part of the teaching and learning programme. The range of techniques recommended includes: experimental investigations, research, collections of work and supervised assessments, and many generic examples are provided but few specific exemplars. The one included for year 9 physics on electric kettles provides a valid test of knowledge, understanding and experimental investigation. There is detailed guidance on setting, judging and reporting assessments, and combining these across a portfolio of work.

Ontario stresses the broad purposes of assessment, expressed as: for learning, as learning and of learning. There are no state examinations, so all assessment is internal. The criteria for the performance are tabulated, under headings such as: knowledge and understanding, thinking and investigation, communication, and application. Four achievement levels are outlined, from 'limited' at level 1 to 'thorough' at level 4. This system is common to all grades and all subjects in science and is clearly adaptable to the different grades and course options. Student achievement must be communicated formally to students and parents by means of the Provincial Report Card. This provides a record of the student's achievement of the curriculum expectations in every course, at particular points in the school year or semester, in the form of a percentage grade.

In Finland there is no cohort-wide testing in science or in any other subject until students reach upper secondary education. Students are assessed by their teachers, who may use tests, amongst other approaches. Progress is reported either in the form of a written description or a grade at the end of the year and on one occasion before that.

In Hong Kong recent reforms have been designed to increase the use of AfL, to diversify assessment modes. Curriculum guides have helpful discussions of the roles of assessment and the value of formative and summative assessment, of school-based assessment and of examinations. For S1-3, at the start of secondary, all assessment is school-based, and 
teachers are encouraged to use a wide range of methods, including oral, practical and written assessments, including projects and portfolios of work.

The extent to which practical work is part of the assessment schemes varies between jurisdictions. Often this is not specifically mentioned, or only as one of a range of methods for SBA/portfolios. The most clearly specified is Queensland, which has criteria, five grades and an exemplar practical assessment; Ontario is not quite so clearly specified but has criteria which imply practical assessment. Abrahams et al. (2013) concluded that countries that carried out direct assessment of practical skills (DAPS) tended to do better in PISA that those that did not. Here, DAPS refers to any form of assessment that requires students, through the manipulation of tangible objects, to demonstrate a practical skill in a manner that can be used to determine their level of competence in that skill. In contrast, the indirect assessment of practical skills (IAPS) refers to any form of assessment in which a student's level of competency is inferred from the data they generate and/or reports of the practical work that they undertook.

Summative assessments are used for transitions, often, in the secondary stage, through tests and examinations. Most jurisdictions expect such an assessment at the end of each grade, though these may be SBA, as noted above. These assessments can take a range of forms and are increasingly using the potential of computers in both responses and marking. In the United States, both Florida and Massachusetts have made extensive use of objective questions for many years. These are typically multiple choice questions which enable objective marking and can readily cover substantial parts of the science curriculum but limit the range of what can be assessed. The review of the spring 2013 Massachusetts test for High School Chemistry was found to be lacking in scientific investigation or application. As a result, there is a move to include more open-ended questions requiring extended answers.

In Shanghai the changes of the past decade have seen a reduction in learning by rote and assessment of factual recall and an increase in the assessment of higher order thinking, contextual application and experimentation. This is reflected in the Zhongkao Grade 9 
examinations, through the skillful design of what are mainly objective questions. The Gaokao leaving examination in physics is a two-hour paper with a range of question types: multiple choice, blank completion, experimental interpretation and calculation). The demand of the questions is generally very high.

In Hong Kong at the end of secondary, S6, there is a new terminal assessment, which consists of examination papers worth $80 \%$ with SBA accounting for the remaining $20 \%$. The SBA is specified to include assessment of both practical and non-practical work. The advice includes how to cater for the needs of students with different aptitudes and abilities, and the value of formative assessment in providing feedback on learning and achievement to students and their parents. The examination papers consist of a mixture of multiple choice questions, structured and longer questions.

In Finland the national matriculation examination comprises four compulsory tests, including natural science subjects as an option. The nature of the examination in physics differs from any of the other jurisdictions reviewed, in a number of ways. All of the questions require extended answers, though some are divided into sections that only require quite short answers. There is a choice of eight from 13 questions, with no restrictions. Some guidance is given about the weighting of the marks and the difficulty of the questions.

Queensland has no compulsory external examinations, though they are available for year 11-12 courses, and there is a proposal that these should be taken by all, to combine with the other assessment outcomes at graduation/HE entry. These include externally moderated SBA, core skills tests and individual projects. Overall, the Queensland system is complex and requires substantial teacher/school input; in this it provides a very good alignment to the curriculum objectives, though it is notable that affective aspects of learning (attitudes and values) are specifically excluded from assessment.

There is a range of descriptions of how outcomes of assessments are awarded. Many refer to grades and standards, more rarely to norm referencing. The Shanghai School Standard 
Examination is taken in ten subjects (including three sciences) at the end of upper secondary and is norm-references (Tan, 2013). The Ontario assessment system makes

much use of standardised tests, with statistical equating with past tests to ensure standards over time and comparability. Hong Kong and New South Wales examinations are stated to be standards-based and Singapore uses grades in ' $\mathrm{O}$ ' level and 'A' level examinations. Japan and the US have no whole cohort national assessments.

Questions that arise in relation to the summative assessment of school science therefore include: whether and how practical work should be assessed; whether assessment should cover values, attitudes, ethical reasoning and socio-scientific capabilities; and what the balance should between between different modes of assessment, ranging from objective (multiple choice) questions to open-ended assignments.

\section{Progression to higher education}

Progression to higher education is usually based, for all subjects, on results of the terminal secondary assessment, though not in all jurisdictions. In New South Wales years 11-12 are assessed in the Higher School Certificate for graduation and entry to HE. This is a combination of SBA and examination, both of which have specified features. Assessment weightings of the internal assessment are stated with, in science, $60 \%$ for scientific enquiry and communication skills. The examination consists of objective response and short answer sections of the paper. In Queensland there is a proposal that the currently optional year 11-12 course examinations should be taken by all, to combine with the other assessment outcomes at graduation/HE entry.

Ontario has no state examinations, so graduation requirements, through course credits from junior (G10) and senior (G12) high school, provide for HE entry selection. In Grades 11 and 12, students take one of five pathways that prepare them for HE entry or employment. Alongside this differentiation, there is a requirement that all students continue to take a relevant science course. 
In the US, admissions tests are used widely, in large part because there is no national system of pre-university testing. Most US universities require applicants to take either the SAT Reasoning Test ('SAT' originally stood for 'Scholastic Aptitude Test') or the ACT (which originally stood for 'American College Testing') - which measures performance in English, Mathematics Science and Reading. There has been considerable debate about the value of university entrance tests in the USA, with growing support for curriculumbased tests assessing 'mastery' of specific subjects within the curriculum. Some of the more selective US universities require applicants to take two to three SAT subject tests.

There are indications that these combinations of graduation certificates, qualifications and entrance examinations to higher education may be simplified, possibly in response to the increasing globalisation. For example, Japan is considering introducing the International Baccalaureate for University Entrance. A question that arises for all jurisdictions is the extent to which it is presumed that a science course at university requires previous school study of that subject to an advanced pre-university level.

\section{Discussion}

Curricula exist in a wide range of forms and there are a number of ways in which they can be developed (cf. Kelly, 2009). Nevertheless, while there are important differences, as reviewed above, in the school science curricula of these eleven jurisdictions, there are many commonalities too. It is noteworthy that many of the jurisdictions are in the process of broadening their aims; there is now more emphasis on scientific literacy, on enquiry and on personal and social goals. School science is seen more as a subject of worth to all students than was once the case (cf. Reiss \& White, 2014).

At the same time we note a degree of convergence across these eleven very different jurisdictions. The Asian ones have made and are making changes to encourage students to be more creative and better able to apply their science knowledge and develop their 
scientific literacy; the 'Western' ones are becoming more knowledge-focused. Perhaps unfairly, we referred above to this tendency as 'regression to the mean'; a more optimistic judgement would consider this convergence to be a positive development, in which East and West take what is best from each other, without abandoning their own roots. Another way of looking at this is to see this as an example of globalisation (cf. Koosimile \& Suping, 2005).

Recent work on post-compulsory aspirations and uptake of science in England emphasises the importance of science capital (Archer et al., 2015) and of students believing that studying science will benefit them extrinsically, e.g. through material rewards (Mujtaba \& Reiss, 2014). Given the rather low levels of interest in school science shown by students in wealthy countries (Bøe et al., 2011), both East and West, such as those represented in our review, it will be interesting to see what effect, if any, such changes have on the post-compulsory uptake of science (cf. Archer et al., 2013).

Finally, we have attempted throughout this article to raise questions suggested by our analyses of the various documents in the jurisdictions we studied. It is noteworthy how rarely such documents either refer explicitly to the situation in other countries or give reasons for the various curriculum decisions that have been made. Attending to these issues would, we feel, strengthen curriculum development in science in the years to come.

\section{References}

Abels, S. (2014) Inquiry-based science education and special needs - teachers' reflections on an inclusive setting, Sisyphus, 2(2), 124-154.

Abrahams, I., Reiss, M. J., \& Sharpe, R.M. (2013). The assessment of practical work in school science. Studies in Science Education, 49, 209-251. 
Archer, L., Osborne, J., DeWitt, J., Dillon, J., Wong, B., \& Willis, B. (2013). ASPIRES: Young people's science and career aspirations, age 10-14. London: King's College London.

Archer, L., Dawson, E., DeWitt, J., Seakins, A., \& Wong, B. (2015) “Science capital”: A conceptual, methodological, and empirical argument for extending bourdieusian notions of capital beyond the arts. Journal of Research in Science Teaching, 52(7), 922-948.

Bøe, M. V., Henriksen, E. K., Lyons, T., \& Schreiner, C. (2011). Participation in science and technology: young people's achievement-related choices in late-modern societies. Studies in Science Education, 47(1), 37-72.

Carless, D. (2011). From testing to productive student learning: Implementing formative assessment in Confucian-Heritage settings. New York: Routledge.

Center for International Education Benchmarking (CIEB) (2015). International Instructional Systems Study: Summary of the findings. Retrieved from http://www.ncee.org/wp-content/uploads/2015/09/International-InstructionalSystem-StudyV2.pdf.

Curdt-Christansen, X. L. \& Silver, R. (2013). New wine into old skins: the enactment of literacy policy in Singapore. Language and Education 7(3), 246-260.

DfE (2012). Review of the National Curriculum in England: What can we learn from the English, mathematics and science curricula of high- performing jurisdictions?

Research report DFE-RR178. London: DfE. Retrieved from https://www.gov.uk/government/uploads/system/uploads/attachment_data/file/1840 64/DFE-RR178.pdf.

Freeman B., Marginson, S., \& Tytler, R. (Eds) (2015). The age of STEM: Policy and practice in science, technology, engineering and mathematics across the world. Abingdon: Routledge.

Harlen, W. et al. (2010). Principles and big ideas of science education, Duns. Available at http://www.ase.org.uk/documents/principles-and-big-ideas-of-scienceeducation/.

Hattie, J. (2009). Visible learning: A synthesis of over 800 meta-analyses relating to achievement. London: Routledge. 
Hogan, D. (2014). Explaining Singapore: A foundation essay for The Conversation. Available at https://theconversation.com/pitches/new.

Isaacs, T., Creese, B. \& Gonzales, A. (2015a) Aligned Instructional Systems: CrossJurisdiction Benchmarking Report, Center for International Education Benchmarking (CIEB). Retrieved from http://www.ncee.org/wpcontent/uploads/2015/09/AIS-Cross-Jurisdiction-Report.pdf.

Isaacs, T., Creese, B. \& Gonzales, A. (2015b) Aligned Instructional Systems: Australia, Center for International Education Benchmarking (CIEB). Retrieved from http://www.ncee.org/wp-content/uploads/2015/09/Australia-JurisdictionReport.pdf.

Isaacs, T., Creese, B. \& Gonzales, A. (2015c) Aligned Instructional Systems: Finland, Center for International Education Benchmarking (CIEB). Retrieved from http://www.ncee.org/wp-content/uploads/2015/09/Finland-Jurisdiction-Report.pdf.

Kelly, A. V. (2009). The curriculum: Theory and practice, $\sigma^{\text {th }}$ edn. Los Angeles CA: Sage.

Koosimile, A. T. \& Suping, S, M. (2005). An examination of the influence of globalisation on science education in Anglophone Sub-Saharan Africa. International Journal of Science Education, 37(14), 2358-2385,

Leong, K. L., Sim, J. B. Y., \& Chua, S. H. (2011). School-based curriculum development in Singapore: Bottom-up perspectives of a top-down policy. Curriculum Perspectives, 31(1), 56-61.

Ministry of Education (2007). The Ontario Curriculum Grades 1-8: Science and Technology. Available at http://www.edu.gov.on.ca/eng/curriculum/elementary/scientec18currb.pdf.

Mujtaba, T. \& Reiss, M. J. (2014). A survey of psychological, motivational, family and perceptions of physics education factors that explain 15 year-old students' aspirations to study post-compulsory physics in English schools. International Journal of Science and Mathematics Education, 12, 371-393.

Reiss, M. J. \& White, J. (2014). An aims-based curriculum illustrated by the teaching of science in schools. The Curriculum Journal, 25, 76-89. 
Ryder, J. \& Banner, I. (2011). Multiple aims in the development of a major reform of the national curriculum for science in England. International Journal of Science Education, 33(5), 709-725.

Takayama, K. (2013). Untangling the global-distant-local knot: the politics of national academic achievement testing in Japan, Journal of Educational Policy, 28(5), 657675.

Tan, C. (2013). Learning from Shanghai: Lessons on achieving educational success. Dordrecht: Springer.

Villanueva, M. G., Taylor, J., Therrien, W. \& Hand, B. (2012). Science education for students with special needs, Studies in Science Education, 48(2), 187-215.

Walker, A. \& Qian, H. (2012). Reform disconnection in China, Peabody Journal of Education, 87(2), 162-177. 


\begin{tabular}{|c|c|c|c|c|c|}
\hline Jurisdiction & $\begin{array}{l}\text { Pre- } \\
\text { primary }\end{array}$ & Primary & $\begin{array}{l}\text { Lower } \\
\text { Secondary }\end{array}$ & $\begin{array}{l}\text { Upper } \\
\text { Secondary }\end{array}$ & $\begin{array}{l}\text { Compulsory } \\
\text { Schooling age }\end{array}$ \\
\hline $\begin{array}{l}\text { New South } \\
\text { Wales }\end{array}$ & $4-5$ & $6-11$ & $12-15$ & $16-18$ & $6-16$ \\
\hline Queensland & $4-5$ & $6-11$ & $12-15$ & 16-18 & $6-16$ \\
\hline Alberta & 5 & $6-11$ & $12-14$ & $15-17$ & $\begin{array}{l}\text { 6-17 (from } \\
2015)\end{array}$ \\
\hline Ontario & $4-5$ & $6-12 / 13$ & Secondary & 13/14-18 & $5-18$ \\
\hline Florida & $4-5$ & $6-10 / 11$ & $11 / 12-13 / 14$ & $14 / 15-18$ & $5-18$ \\
\hline Massachusetts & $4-5$ & 6-10/11 & $11 / 12-13 / 14$ & $14 / 15-18$ & $5-18$ \\
\hline Finland & $5-6$ & $7-12$ & $13-15$ & 16-18 & $7-17$ \\
\hline Japan & & $6-11$ & $12-14$ & $15-18$ & $6-15$ \\
\hline Singapore & & 6-12/13 & Secondary & 13/14-17or18 & $6-12 / 13$ \\
\hline Hong Kong & & $6-11$ & $12-14$ & $15-18$ & $6-15$ \\
\hline Shanghai & & $6-11$ & $12-14$ & $15-18$ & $6-15$ \\
\hline
\end{tabular}

Table 1: Ages of school transitions (years) 